\title{
Study of Chloride Transport Across the Rabbit Cortical Collecting Tubule
}

\author{
Michael J. Hanley and Juha P. KoKko, Department of Internal Medicine, \\ The University of Texas Health Science Center at Dallas, \\ Dallas, Texas 75235
}

A B S T RACT Recent micropuncture studies have suggested that the collecting tubule may be involved in the regulation of extracellular fluid volume. The present studies were designed to evaluate chloride transport across the in vitro-perfused rabbit cortical collecting tubule inasmuch as chloride ion would ultimately affect extracellular fluid volume. The tubules were perfused and bathed with artificial solutions simulating ultrafiltrate. Four groups of studies were conducted. In groups one and two, tubules from rabbits not receiving desoxycorticosterone (DOCA) were compared to tubules from rabbits which had received DOCA $(5 \mathrm{mg} /$ day) for $1 \mathrm{wk}$. In groups three and four, tubules were obtained only from rabbits not receiving DOCA. In group one, sequential bidirectional chloride fluxes were measured. The ratio of chloride efflux to influx was $0.99 \pm 0.04$ in tubules obtained from rabbits not receiving DOCA whereas it was $1.28 \pm 0.09$ in tubules obtained from rabbits receiving DOCA, suggesting stimulation of net chloride flux under these conditions. In group 2, chemical chloride concentration and osmolality of the collected fluid were measured. Neither the chemical chloride concentration nor the osmolality of the collected fluid decreased significantly below their respective perfusion fluid values in tubules from nonDOCA-treated rabbits but there was a significant decrease in the chemical chloride concentration (10-42 meq/liter) and osmolality (10-42 mosmol/ $\mathrm{kg} \mathrm{H}_{2} \mathrm{O}$ of the collected fluid in tubules from DOCA-treated rabbits. In group three, unidirectional chloride permeabilities from lumen-to-bath were determined during the passage of current down the perfusion pipette. The alterations of the average lumen potential, $-35 \pm 4$ and $+28 \pm 2$ $\mathrm{mV}$, did not influence unidirectional chloride move-

This work was presented, in part, at the 69th Annual Meeting of the American Society for Clinical Investigation, Washington, D. C., May 1977.

Received for publication 14 June 1977 and in revised form 3 March 1978. ment suggesting that the cortical collecting tubule is quite impermeable to chloride. In group four, unidirectional chloride permeability from lumen-to-bath was measured before and after substitution of $\mathrm{NaCH}_{3} \mathrm{SO}_{4}$ for sodium chloride in the bath. Replacement of chloride by $\mathrm{CH}_{3} \mathrm{SO}_{4}$ reversibly decreased the apparent chloride permeability from $2.41 \pm 0.50$ to $0.69 \pm 0.08\left(\times 10^{-5} \mathrm{~cm} / \mathrm{s}\right)$ demonstrating that ${ }^{36} \mathrm{Cl}$ permeability is dependent on the chemical concentration of chloride.

The current studies demonstrate that: $(a)$ the cortical collecting tubule is able to reabsorb salt under the modulation of circulating mineralocorticoids and, thus, may participate in overall volume homeostasis; $(b)$ the chloride permeability and the major portion of isotopic chloride flux across the cortical collecting tubule is via exchange diffusion; and $(c)$ under certain circumstances the cortical collecting tubule may act as a diluting segment.

\section{INTRODUCTION}

For several years, evidence has been advanced suggesting that the collecting tubule is involved in the regulation of extracellular fluid volume (1-3). Because chloride is the principal extracellular anion, it is quite likely that the collecting tubule may, in part, control extracellular fluid by regulating reabsorption of chloride. Although the characteristics of chloride transport across many natural epithelia (4-6) and artificial membranes (7) have been examined in some detail, very little information is available regarding the handling of chloride by the mammalian distal nephron. The exact role of endogenous mineralocorticoid in the maintenance of extracellular fluid volume has likewise been intensively examined but not positively delineated $(8-10)$. The present studies were therefore undertaken to characterize chloride transport across the rabbit cortical collecting tubule and to examine the effect of mineralocorticoid on net chloride transport. 


\section{METHODS}

Segments of cortical collecting tubule $(\mathrm{CCT})^{1}$ were perfused in vitro by the technique described $(8,11,12)$. Female New Zealand rabbits weighing $1.5-2.5 \mathrm{~kg}$ were used in all experiments. All rabbits were fed a standard laboratory diet and had free access to water. Those animals in which a maximum mineralocorticoid response was required were given in addition deoxycorticosterone acetate (DOCA) $5 \mathrm{mg} /$ day i.m. for $1 \mathrm{wk}$ before experimentation. After guillotine decapitation, the kidney was quickly removed and cut into $1-2-\mathrm{mm}$ slices. A segment of CCT 1.8-3.0 mm long was dissected out in a chilled dish of artificial ultrafiltrate with $5 \% \mathrm{vol} / \mathrm{vol}$ fetal calf serum. The tubules were perfused with an artificial ultrafiltrate of the following composition: $\mathrm{NaCl} 105 \mathrm{mM}, \mathrm{KCl} 5 \mathrm{mM}$, $\mathrm{NaHCO}_{3} 25 \mathrm{mM}, \mathrm{Na}_{2} \mathrm{HPO}_{4} 2.3 \mathrm{mM}, \mathrm{Na}$ acetate $10 \mathrm{mM}, \mathrm{MgSO}_{4}$ $1 \mathrm{mM}, \mathrm{CaCl}_{2} 1.8 \mathrm{mM}$, glucose $8.3 \mathrm{mM}$, alanine $5 \mathrm{mM}$, total osmolality $298 \pm 5 \mathrm{mosmol} / \mathrm{kg} \mathrm{H}_{2} \mathrm{O}$. The tubules were bathed with a solution of identical composition to which $5 \% \mathrm{vol} / \mathrm{vol}$ fetal calf serum had been added (unlesss otherwise indicated). The transtubular potential difference $(\mathrm{PD})$ was measured by the techniques reported (13). All studies were performed at $37^{\circ} \mathrm{C}$. The permeability coefficient for ${ }^{36} \mathrm{Cl}$ (ICN Pharmaceuticals, Inc., Irvine, Calif.) was measured by methods described (14). Bidirectional fluxes of chloride were measured in the same tubule by successive determinations of each unidirectional flux. In any series of experiments the order of measurement of efflux and influx was varied to obviate a systematic source of bias. Undirectional efflux was measured by adding ${ }^{125}$ I-iothalamate (Glofil-125, Abbott Diagnostics, North Chicago, Ill.) to a specially prepared enriched ${ }^{36} \mathrm{Cl}$ perfusate while the bath was ${ }^{36} \mathrm{Cl}$ free. The perfusate was prepared by adding relatively high specific activity $(115 \mu \mathrm{Ci} / \mathrm{mg}) 1 \mathrm{M} \mathrm{NaCl}$ to hypotonic fluid. The final electrolyte concentration of this perfusate was subsequently adjusted by the addition of appropriate amounts of various electrolytes to eliminate electrolyte concentration gradient between the bathing fluid. Unidirectional isotopic fluxes for chloride were expressed in terms of apparent permeability coefficients $(\mathrm{cm} / \mathrm{s})$ according to the following expression (14):

$$
\mathrm{P}^{\prime}{ }_{\mathrm{lb}}=\frac{\mathrm{Vi}}{\mathrm{A}} \ln \frac{\mathrm{Ci}^{*}}{\mathrm{Co}^{*}},
$$

where $\mathrm{A}$ is the area of the tubule; $\mathrm{Vi}$, perfusion rate; $\mathrm{Ci}^{*}$, counts per minute per milliliter of isotope in the perfusate; and $\mathrm{Co}^{*}$, counts per minute per milliliter of isotope in the collected fluid. In those experiments in which inward permeability $\mathbf{P}_{b 1}^{\prime}, \mathrm{cm} / \mathrm{s}$ ) was measured in the same tubule the apparent permeability coefficient was calculated by (14):

$$
\mathrm{P}_{\mathrm{bl}}^{\prime}=\frac{\mathrm{Co}}{\mathrm{Cb}^{*}} \frac{\mathrm{P}_{\mathrm{lb}}{ }^{\prime}}{1-\exp \cdot\left(-\mathrm{AP}_{\mathrm{lb}} / \mathrm{V}\right)},
$$

where Co* counts per minute per milliliter of isotope in the collected fluid; $\mathrm{Cb}^{*}$, counts per minute per milliliter of isotope in the bath; $\mathrm{A}$, area of tubule; $\mathrm{V}$, mean flow rate. No experiments were used unless the change or appearance of counts exceeded five times background. Chloride fluxes were determined by multiplying the apparent permeability coefficients by the $[\mathrm{Cl}]$ in the perfusate and bath respectively with normalization to unit tubule length. Unless otherwise specified, perfusion rates were $3-8 \mathrm{nl} / \mathrm{min}$ and experiments were discarded if significant water flow $(> \pm 0.1 \mathrm{nl} / \mathrm{mm}$ per $\mathrm{min}$ ) occurred as determined by the ${ }^{125}$ I-iothalamate volume marker.

${ }^{1}$ Abbreviations used in this paper: bl, bath-to-lumen; CCT, cortical collecting tubule; $\mathrm{Cl}^{-}$, chloride ion concentration; DOCA, deoxycorticosterone acetate; J, flux; lb, lumen-to-bath; $\mathrm{P}^{\prime}$, permeability; PD, potential difference.
In those experiments that sought to determine an effect of a PD change on ${ }^{36} \mathrm{Cl}$ efflux the potential across the tubule was changed and maintained by an external current source and circuit as described by Helman et al. (15). The length constant of the cortical collecting tubule at $37^{\circ} \mathrm{C}$ was determined by a method similar to that described by these same authors. This consisted of simultaneously measuring a current-induced potential change in the tubule at the tip of the perfusion pipette and at the distal collecting end. These two experimentally determined potential changes together with the micrometermeasured tubular length allowed the determination of the length constant according to the following relation (15): $\mathrm{L} / \lambda=$ $\cosh ^{-1}(\Delta \mathrm{V}[\mathrm{O}] / \Delta \mathrm{V}[\mathrm{L}])$, where $\mathrm{L}$ is the tubular length, $\Delta \mathrm{V}(\mathrm{O})$ and $\Delta \mathrm{V}(\mathrm{L})$ are the voltage changes at the tip of the perfusion pipette, and at the distal end of the tubule and $\lambda$ is the length constant. The average potential change produced over the tubule was calculated with an integrated form of the same expression.

$$
\Delta \overline{\mathrm{V}}=\frac{\int_{0}^{\mathrm{L}} \mathrm{V}(\mathrm{x}) \mathrm{dx}}{\mathrm{L}},
$$

where $\Delta \bar{V}$ is the average potential change induced over the entire tubule, and $V(x)$ is $\Delta V(O) / \cosh (X / \lambda)$.

Osmolality of all solutions was determined by an osmometer (Advanced Instruments, Inc., Needham Heights, Mass.). Osmolality of collected fluid was determined by a modified Clifton nanoliter osmometer (Clifton Technical Physics, Hartford, N. Y.) (11). The analysis of chloride ion concentrations in the collected fluid, perfusate, and bath was performed by the microelectrometric titration method of Ramsay et al. (16). The isotopic data of each tubule were obtained as a mean of two to four collection periods. The results in turn are expressed as mean $\pm S E$ of the number of tubules $(n)$ studied. The statistics were calculated as paired or unpaired $t$ test analysis unless otherwise stated (17). Samples for chloride and osmolality determinations were collected under oil. When a sample with an appropriate flow rate was collected, chloride and osmolality were determined from the single sample. If determination of both parameters from the single sample was not possible as a result of technical handling errors the experiment was discarded. Each chloride and osmolality value is an average of two or three separate determinations from the single sample. Collections from DOCA and non-DOCA tubules were obtained at equivalent times after the initiation of perfusion to obviate differences as a result of antidiuretic hormone.

\section{RESULTS}

Determination of bidirectional Cl permeability. Net chloride efflux from the CCT was examined isotopically in two groups. First, tubules were examined from rabbits fed a normal laboratory diet of high salt content. It has been shown in our laboratory that tubules harvested from such animals are in a relatively mineralocorticoid suppressed state (8). This condition was qualitatively reflected in the low average transepithelial difference recorded in these tubules. Second, tubules were examined from rabbits which, in addition to the normal diet, were treated with DOCA $5 \mathrm{mg} /$ day i.m. for $1 \mathrm{wk}$ before experimentation. These tubules were assumed to be under a greatly augmented mineralocorticoid stimulus as reflected in the greatly increased baseline transepithelial potentials. The results of these experiments are shown in Table I. The first nine experi- 
TABLE I

Bidirectional Chloride Permeabilities Across the Rabbit CCT in the Presence and Absence of DOCA Stimulation

\begin{tabular}{lcccccc}
\hline \multicolumn{1}{c}{ Exp. } & $\mathrm{P}_{\mathrm{bb}}{ }^{\prime}$ & $\mathrm{J}$ & $\mathrm{P}_{\mathrm{bb}}{ }^{\prime}$ & $\mathrm{J}_{\mathrm{bl}}$ & $\overline{\mathrm{PD}}$ & $\mathrm{P}_{\mathrm{bb}}{ }^{\prime} / \mathrm{P}_{\mathrm{b}^{\prime}}$ \\
\hline & $c m / s \times 10^{-5}$ & $p e q / c m / s$ & $c m / s \times 10^{-5}$ & $p e q / c m / s$ & $m V$ & \\
1 (ND) & 0.236 & 1.63 & 0.203 & 1.40 & -5 & 1.16 \\
2 (ND) & 2.16 & 14.9 & 2.40 & 16.6 & -13 & 0.90 \\
3 (ND) & 2.47 & 17.1 & 2.44 & 16.9 & -4 & 1.01 \\
4 (ND) & 4.15 & 28.7 & 4.58 & 31.6 & +1 & 0.91 \\
5 (ND) & 1.45 & 10.0 & 1.66 & 11.5 & -2 & 0.87 \\
6 (ND) & 2.45 & 16.9 & 2.31 & 16.0 & -3 & 1.06 \\
7 (ND) & 3.05 & 21.1 & 2.74 & 18.9 & -6 & 1.11 \\
8 (ND) & 0.70 & 4.84 & 0.90 & 6.22 & -45 & 0.79 \\
9 (ND) & 1.40 & 9.67 & 1.24 & 8.57 & -8 & 1.13 \\
Mean \pm SEM & - & - & - & - & - & $0.99 \pm 0.04$ \\
10 (D) & 1.02 & 7.05 & 0.805 & 5.56 & -39 & 1.27 \\
11 (D) & 2.15 & 14.9 & 1.80 & 12.4 & -31 & 1.19 \\
12 (D) & 1.23 & 8.50 & 0.797 & 5.51 & -21 & 1.54 \\
13 (D) & 0.897 & 6.20 & 0.791 & 5.46 & -30 & 1.13 \\
Mean \pm SEM & - & - & - & - & - & $1.28 \pm 0.09$ \\
\hline
\end{tabular}

Abbreviations: ND, non DOCA-treated animals; D, DOCA-treated animals.

ments show results obtained in the nonstimulated tubules. The average lumen-to-bath (lb):bath-to-lumen (bl) permeability ratio was $0.99 \pm 0.04$. Statistically this number was not different from one and therefore no net chloride transport could be detected isotopically. The results obtained from DOCA-stimulated tubules are shown as exp. 10-13. In these experiments, the average lumen-to-bath:bath-to-lumen permeability ratio was $1.28 \pm 0.09$, a value statistically different from the nonstimulated tubules $(P<0.01)$, but not statistically different from one $(P<0.06)$ which, therefore, is only suggestive evidence for net chloride efflux $(J)$. On the other hand, if the mean-paired difference $\left(\mathrm{J}_{\mathrm{lb}}-\mathrm{J}_{\mathrm{bl}}\right)$ is normalized by dividing by $\mathrm{J}_{\mathrm{b} 1}$ then $\mathrm{J}_{\mathrm{lb}}$ is $28.7 \pm 8.9 \%$ greater than $\mathrm{J}_{\mathrm{bl}}(P<0.025)$ which implies net chloride efflux with DOCA treatment. However, the presence of a large exchange diffusion component of chloride flux makes the flux ratio an insensitive marker of net chloride movement.

PD Effect on Chloride Permeability. In an attempt to determine whether the transtubular PD influences the apparent isotopic chloride permeability, an external current was passed down the perfusing pipette by a bridge circuit (15). It was then possible to alter the base-line PD in nonstimulated tubules and determine the effect of such a perturbation on unidirectional lumen-to-bath chloride movement. In a separate series of experiments (six tubules) the length constant was determined in the cortical collecting tubule at $37^{\circ} \mathrm{C}$ and found to be $0.61 \pm 0.03 \mathrm{~mm}$. This is considerably shorter than the value Helman et al. (15) found in this segment at $25^{\circ} \mathrm{C}(\lambda=1 \mathrm{~mm})$. This value at $37^{\circ} \mathrm{C}$ was then used to calculate the average potential perturbation over the entire length of the tubule by the applied current. In four such experiments (Fig. 1), the average negative potential perturbation was $-35 \pm 4 \mathrm{mV}\left(\mathrm{R}_{\mathrm{t}}=4.4 \pm 0.5 \times 10^{4}\right.$ $\Omega \mathrm{cm}$ ) and the average positive potential perturbation was $+28 \pm 2 \mathrm{mV}$ (transepithelial resistance $=4.4 \pm 0.5 \times 10^{4}$ $\Omega \mathrm{cm}$ ). The imposed potential did not detectably alter the chloride lumen-to-bath apparent permeability (solid lines). This was verified by two-way analysis of variance by rank (17). If the nonexchange diffusion component of chloride flux $\left(\mathrm{P}^{\prime}=0.69 \times 10^{-5} \mathrm{~cm} / \mathrm{s}\right)($ Fig. 2) was influenced by the potential, the apparent permeability should have been augmented by a negative perturbation potential and inhibited by a positive perturbation potential (dashed lines). This conclusion is based on the assumption that the applied current moves

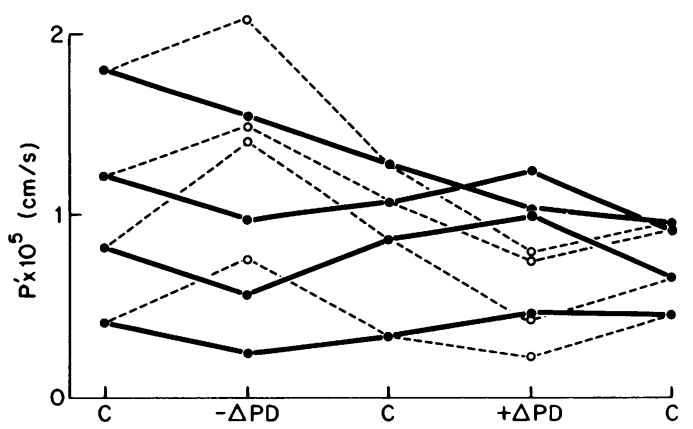

FIGURE 1 Influence of transepithelial potential on chloride $\mathrm{P}^{\prime}{ }_{1 \mathrm{~b}} . \mathrm{C}=$ control (spontaneous $\mathrm{PD} ;-\Delta \mathrm{PD}=$ lumen made $35 \pm 4$ $\mathrm{mV}$ more negative than spontaneous $\mathrm{PD} ;+\Delta \mathrm{PD}=$ lumen made $28 \pm 2 \mathrm{mV}$ more positive than spontaneous PD. Solid lines $=$ experimental observations. Dashed lines $=$ calculated perturbations of $\mathbf{P}^{\prime}{ }_{\mathrm{lb}}$. 


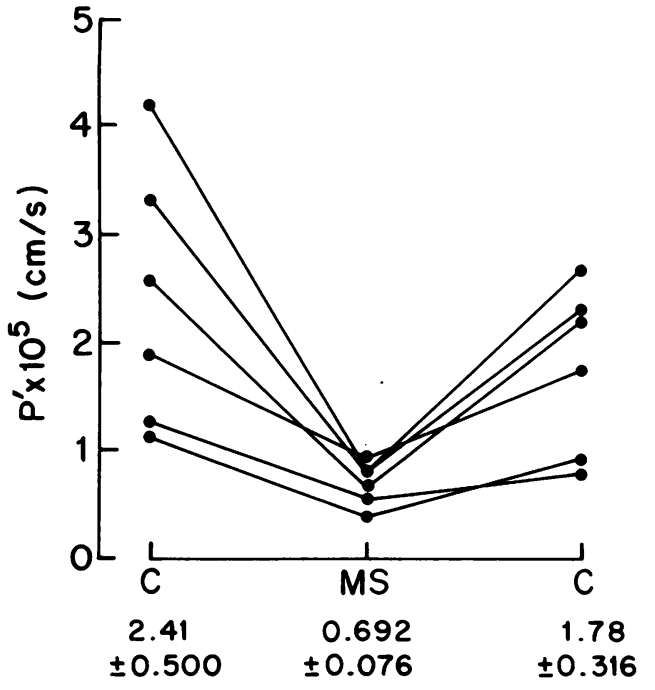

FIGURE 2 Effect of removing $\mathrm{Cl}^{-}$from the bath on chloride $\mathrm{P}^{\prime}{ }_{\mathrm{bl}}$. $\mathrm{C}=$ control - chloride present in bath and perfusate; MS = chloride replaced in the bath by methyl sulfate, perfusate containing chloride.

sodium through an active pathway which then passively affects chloride flux. Inasmuch as the appropriate flux alteration was not observed, we suggest that the induction of a negative potential by mineralocorticoid administration is probably not the sole mechanism by which this hormone mediates chloride transport and analogies between the CCT and the frog skin may be too simplistic.

Evidence for exchange diffusion. In a previous study, the measured isotopic chloride flux across the CC'T was compared with the estimated chloride ion conductance (18). The majority $(85 \%)$ of the isotopic chloride flux was found to be electrically silent, and a large exchange diffusion component of chloride ion tränsport was postulated. In the present experiments the presence of exchange diffusion was examined by measuring the effect of removing chloride from the bath on isotopic chloride lumen-to-bath permeability. This series of experiments was performed on tubules obtained from rabbits on a regular laboratory diet (Fig. 2 ). The tubules were initially perfused and bathed in an artificial ultrafiltrate solution. The apparent permeability values obtained during this control period averaged $2.41 \pm 0.50$ and were similar to the range of values observed in other experiments. Upon substitution of bath chloride ion with the methyl sulfate ion, the apparent chloride lumen-to-bath permeability decreased to $0.69 \pm 0.08 \times 10^{-5} \mathrm{~cm} / \mathrm{s} \quad(P<0.02)$. Although there exists a large variation in intertubular ${ }^{36} \mathrm{Cl}$ apparent permeability coefficients (consistent within each tubule ), once the exchange diffusion of chloride is eliminated, the lumen-to-bath ${ }^{36} \mathrm{Cl}$ apparent permeability coefficients fall to values with a very narrow range. Bathing the tubules with control artificial ultrafiltrate solution caused a significant recovery $(P<0.01)$ of isotopically measured chloride lumen-to-bath permeability $\left(1.78 \pm 0.32 \times 10^{-5} \mathrm{~cm} / \mathrm{s}\right)$. These observations confirm the existence of the previously postulated (18) chloride exchange diffusion and in addition explain the wide range of isotopic permeabilities observed in Table I. The exchange diffusion experiments encompassed a wide range of chloride permeabilities which were reduced to a uniform low value by chloride removal from the bath. Chloride transport across the CCT therefore involves a variable exchange diffusion component.

Chloride ion concentration $\left[\mathrm{Cl}^{-}\right]$and osmolality changes generated by the CCT. Because a variable exchange diffusion complicates the interpretation of chloride flux data, tubules were perfused at low flow rates $(2-4 \mathrm{nl} / \mathrm{min})$ and the collected fluid was analyzed for both chemical chloride concentration $\left[\mathrm{Cl}^{-}\right]$and osmolality. Studies were performed on tubules: $(a)$ from rabbits on a regular laboratory diet and $(b)$ from rabbits on a regular laboratory diet plus DOCA $5 \mathrm{mg} /$ day i.m. for $1 \mathrm{wk}$ before experimentation (Table II). In tubules obtained from nonstimulated animals (exp. 1-6) a small decrease in $\left[\mathrm{Cl}^{-}\right](2.3 \pm 1.4 \mathrm{meq} / \mathrm{liter})$ and osmolality (1.0 \pm 2.0$)$ mosmol $/ \mathrm{kg} \mathrm{H}_{2} \mathrm{O}$ was observed. This effect was greatly amplified in those tubules obtained from rabbits subjected to an intense mineralocorticoid stimulation (exp. 7-12); $\left[\mathrm{Cl}^{-}\right]$decreased $22 \pm 5.5 \mathrm{meq} / \mathrm{liter}$ and osmolality decreased $32.0 \pm 5.2 \mathrm{mosmol} / \mathrm{kg} \mathrm{H}_{2} \mathrm{O}$. These results are significantly different $(P<0.02)$ from those obtained from non-DOCA rabbits. The cortical collecting tubule thus possesses the properties of a segment capable of tubular fluid dilution.

\section{DISCUSSION}

The present in vitro studies disclose that the cortical collecting tubule of the rabbit is capable of net lumento-bath chloride transport. It was further shown that this capability is augmented by exogenously administered DOCA. In addition, these studies confirm that the major fraction of the isotopic flux is secondary to exchange diffusion. Once the exchange diffusion is eliminated, it was shown that the cortical collecting tubule is relatively impermeable to chloride to the extent that net chloride transport is not influenced significantly by large variations in transtubular potential difference. The combination of the above described membrane characteristics together with previously demonstrated low osmotic water permeability (19) allows the cortical collecting tubule to act as a diluting segment in the absence of antidiuretic hormone. It has geen generally accepted that isotopic flux measurements can be used to examine for the presence of net ion transport. We would agree with this view in the absence of exchange diffusion. However, if a large component of the unidirectional flux is secondary to exchange diffusion as previous studies suggest (18) and present studies di- 
TABLE II

Changes in $\left(\mathrm{Cl}^{-}\right)$and Osmolality Generated by the Rabbit CCT in the Presence and Absence of DOCA Stimulation

\begin{tabular}{lccccccc}
\hline \multicolumn{1}{c}{ Exp. } & $\begin{array}{c}\text { Perfusion } \\
\text { rate }\end{array}$ & $\begin{array}{c}\text { Perfusion } \\
\left(\mathrm{Cl}^{-}\right)\end{array}$ & $\begin{array}{c}\text { Perfusion } \\
\text { mosmol }\end{array}$ & $\begin{array}{c}\text { Collected } \\
\left(\mathrm{Cl}^{-}\right)\end{array}$ & $\begin{array}{c}\text { Collected } \\
\text { mosmol }\end{array}$ & $\Delta\left(\mathrm{Cl}^{-}\right)$ & $\Delta$ mosmol $^{-}$ \\
\hline & nl/min & meq/liter & mosmol/kg $\mathrm{H}_{2} \mathrm{O}$ & meq/liter & mosmollkg $\mathrm{H}_{2} \mathrm{O}$ & meq/liter & mosmol/kg $\mathrm{H}_{2} \mathrm{O}$ \\
1 (ND) & 2.0 & 98 & 291 & 101 & 287 & +3 & +4 \\
2 (ND) & 2.0 & 98 & 296 & 92 & 289 & -6 & -7 \\
3 (ND) & 2.0 & 105 & 293 & 102 & 298 & -3 & +5 \\
4 (ND) & 2.5 & 110 & 296 & 104 & 300 & -6 & +4 \\
5 (ND) & 2.5 & 99 & 290 & 97 & 291 & -2 & +1 \\
6 (ND) & 2.0 & 103 & 298 & 103 & 293 & 0 & -5 \\
Mean \pm SEM & & & & & & $-2.3 \pm 1.4$ & $-1 \pm 2.0$ \\
7 (D) & 3.5 & 115 & 294 & 99 & 252 & -16 & -42 \\
8 (D) & 3.5 & 110 & 294 & 100 & 268 & -10 & -26 \\
9 (D) & 2.0 & 108 & 292 & 72 & 259 & -36 & -33 \\
10 (D) & 2.0 & 108 & 292 & 66 & 258 & -42 & -34 \\
11 (D) & 3.0 & 114 & 295 & 96 & 285 & -18 & -10 \\
12 (D) & 2.0 & 110 & 296 & 98 & 250 & -12 & -46 \\
Mean \pm SEM & & & & & & $-22 \pm 5.5$ & $-32 \pm 5.2$ \\
\hline
\end{tabular}

Abbreviations: ND, non DOCA-treated animals; D, DOCA-treated animals.

rectly demonstrate (Fig. 2), then it is possible that the large exchange diffusion component can completely obscure the presence of differences in unidirectional fluxes. Estimates from the present studies show that exchange diffusion can contribute up to $90 \%$ of the transepithelial isotopic chloride flux, in substantial agreement with earlier indirect estimates based on electrical measurements (18). The significant feature of the present studies is that this component is not a fixed fraction of the isotopic flux but varies substantially from tubule to tubule. As far as can be determined from the present investigation, this variability cannot be correlated with any extrinsic or intrinsic parameter of the animal. Therefore, the control of exchange diffusion and its biological significance in the CCT is totally unknown. A large step in the further examination of chloride transport across this segment would be made if exchange diffusion could be physiologically eliminated without altering other transport processes. If exchange diffusion flux cannot be eliminated, evidence for active chloride transport across the CCT must be based on electrophysiologic measurements of transepithelial PD and concentration distributions across the tubule.

Because the nonexchange diffusion component of chloride transport is invariably a minority of the measured flux, the influence of a potential will be difficult to examine. It can be noted, however, that the present PD perturbation experiments were performed on tubules that had a low base-line apparent permeability to ${ }^{36} \mathrm{Cl}$ and therefore, presumably had a low component of exchange diffusion. Even under these circumstances no statistically significant change was noted in the apparent lumen-to-bath permeability with potential. The
CCT epithelial tight junctions are presumed to be relatively impermeable to chloride ions and the vast majority of chloride transport across the CCT involves a carrier-mediated transcellular route. The great majority of this transport is exchange diffusion; whether the remainder is an active chloride transport process or a carrier-coupled sodium and chloride transport process remains to be determined.

That the CCT is capable of acting as a diluting segment is not a totally new concept but it has not been examined directly in previous investigations. Jamison and Lacy (20) examined Brattleboro rats and found evidence for dilution by the collecting tubule in these animals while they were undergoing a maximum water diuresis. Experimental conditions in this indirect study were similar to the current investigations in that both studies examined collecting tubule function in the absence of antidiuretic hormone. The present direct examination of the collecting tubule clearly demonstrates that under DOCA stimulation a diluting capacity of this segment can be elicited. Though Grantham et al. (3) have found a one-to-one coupling of sodium reabsorption and potassium secretion, the generation of a dilute fluid by the CCT in the present study clearly demonstrates that tight coupling of sodium for potassium does not always exist in this segment.

The mineralocorticoid effect observed in the present study is completely consistent with the observations of Uhlich et al. (9). They examined the effect of various aldosterone states on sodium reabsorption across the rat collecting duct. By means of elegant simultaneous papillary micropuncture and vasa recta perfusions, these authors came to the conclusion that aldosterone caused an increase of the intrinsic sodium transport capacity 
and a decrease of the leak permeability for sodium ions. The present direct in vitro studies of the CCT support this conclusion. Chloride ion transport was the parameter specifically measured and no attempt was made in the current investigation to delineate the driving forces responsible for net chloride movement. $\mathrm{Al}$ though mineralocorticoids stimulate sodium transport, the possibility exists that it also affects carrier-mediated chloride transport. The more lumen-negative potential induced by DOCA administration (Table I) could, in itself, explain the increment in stimulated chloride efflux but no direct effect of potential alone could be demonstrated in the present studies which suggests that mineralocorticoids affect chloride transport as well as sodium transport.

Another question that deserves consideration is the correlation between chloride changes and osmolality changes observed in the CCT in the present study. Although it is clear that steroid administration dramatically increases chloride efflux and decreases osmolality, whether this chloride efflux is solely responsible for the observed osmolality changes cannot be determined with certainty. On average, the osmolality changes are not sufficient to explain the chloride efflux. This raises the possibility that the concentration of another anion, possibly bicarbonate, may be increasing along the CCT. This question can only be answered by direct study of simultaneous chloride and bicarbonate concentrations in the collected fluid.

In summary, the present studies demonstrate that the CCT is able to reabsorb salt under the modulation of circulating mineralocorticoids. In the absence of mineralocorticoid, there was only minimal if any net salt movement across the CCT whereas in the presence of exogenously administered DOCA there was significant net salt efflux. Thus, these studies suggest that the CCT may participate in overall volume homeostasis. The potential significance of these findings is enhanced by the observation that intravenously administered aldosterone in human subjects undergoing a water diuresis produces urinary dilution without affecting glomerular filtration rate or renal plasma flow (21). Whether the diluting capacity of the collecting tubule is of physiological significance as an additional energy source for the operation of the countercurrent multiplication system awaits further systematic examination.

\section{ACKNOWLEDGMENTS}

The authors wish to thank Jan Hawkins, Jean Clark, Rebecca Himmel, and Virginia Borcoman for their expert technical assistance.

This work was supported in part by National Institute of Arthritis and Metabolic Diseases research grant 2 RO1 AM 14677 and National Institute of Arthritis and Metabolic Diseases training grant 1 T32 AM 07257.

\section{REFERENCES}

1. Diezi, J., P. Michoud, J. Aceves, and G. Giebisch. 1973. Micropuncture study of electrolyte transport across the papillary collecting duct of the rat. Am. J. Physiol. 224: 623-634.

2. Stein, J. H., and H. J. Reineck. 1974. The role of the collecting duct in the regulation of excretion of sodium and other electrolytes. Kidney Int. 6: 1-9.

3. Grantham, J. J., M. B. Burg, and J. Orloff. 1970. The nature of transtubular $\mathrm{Na}$ and $\mathrm{K}$ transport in isolated rabbit renal collecting tubules. J. Clin. Invest. 49: 1815-1826.

4. Forte, J. G. 1969. Three components of $\mathrm{Cl}^{-}$flux across the isolated bullfrog gastric mucose. Am. J. Physiol. 216: 167-174.

5. Finn, A. L., J. S. Handler, and J. Orloff. 1967. Active chloride transport in the isolated toad bladder. Am. J. Physiol. 213: 179-184.

6. Alvarado, R. H., T. H. Dietz, and T. L. Mullen. 1975. Chloride transport across isolated skin of Rana pipiens. Am. J. Physiol. 229: 869-876.

7. Andreoli, T. E. and M. L. Watkins. 1973. Chloride transport in porous lipid bilayer membranes. J. Gen. Physiol. 61: 809-830.

8. Gross, J. B., M. Imai, and J. P. Kokko. 1975. A functional comparison of the cortical collecting tubule and the distal convoluted tubule. J. Clin. Invest. 55: 1284-1294.

9. Uhlich, E., C. A. Baldamus, and K. J. Ullrich. 1969. Einfluss von Aldosteron auf den Natriumtransport in den Sammelrohren der Saügetierniere. Pflugers Arch. Eur. J. Physiol. 308: $111-126$.

10. Uhlich, E., R. Halback, and K. J. Ullrich. 1970. Einfluss von Aldosteron auf den Ausstrom markierten Natriums aus den Sammelrohren der Ratte. Pflugers Arch. Eur. J. Physiol. 320: 261-264.

11. Kokko, J. P. 1970. Sodium chloride and water transport in the descending limb of Henle. J. Clin. Invest. 49: $1838-1846$.

12. Kokko, J. P. 1972. Urea transport in the proximal tubule and descending limb of Henle. J. Clin. Invest. 51: 19992008.

13. Kokko, J. P. 1973. Proximal tubule potential difference. Dependence on glucose, $\mathrm{HCO}_{3}$ and amino acids. J. Clin. Invest. 52: $1362-1367$.

14. Imai, M., and J. P. Kokko. 1974. Sodium chloride, urea and water transport in the thin ascending limb of Henle. J. Clin. Invest. 53: 393-402.

15. Helman, S. I., J. J. Grantham, and M. B. Burg. 1971. Effect of vasopressin on electrical resistance of renal cortical collecting tubules. Am. J. Physiol. 220: 1825-1832.

16. Ramsay, J. A., R. H. J. Brown, and P. C. Croghan. 1955. Electrometric tibation of chloride in small volumes. $J$. Exp. Biol. 32: 822-829.

17. Siegel, S. 1956. Nonparametric statistics for the behavioral sciences. McGraw-Hill, Inc., New York. 162.

18. Stoner, L. C., M. B. Burg, and J. Orloff. 1974. Ion transport in cortical collecting tubule; effect of amiloride. Am. J. Physiol. 227: 453-459.

19. Schafer, J. A., and T. E. Andreoli. 1972. Cellular constraints to diffusion. The effect of antidiuretic hormone on water flows in isolated mammalian collecting tubules. $J$. Clin. Invest. 51: 1264-1278.

20. Jamison, R. L., and F. B. Lacy. 1972. Evidence for urinary dilution by the collecting tubule. Am. J. Physiol. 223: 898-902.

21. Sonnenblick, E. H., S. K. Cannon, and J. H. Laragh. 1961. The nature of the action of intravenous aldosterone: Evidence for a role of the hormone in urinary dilution.J. Clin. Invest. 40: 903-913. 